\title{
CLINICAL EVALUATION OF METHOXYFLURANE IN OBSTETRICAL ANAESTHESIA: A REPORT ON 500 CASES*
}

Michel Boisvert, M.D., B.PH., ANd Fernando Hudon, M.D., F.R.C.P.(c)

Ever SINCE the introduction of methoxyflurane (Penthrane, Abbott), many reports have been published on its characteristics, advantages, and disadvantages in surgical anaesthesia. But, aside from a brief reference, ${ }^{1}$ the first preliminary report on the somewhat extensive use of methoxyflurane in general anaesthesia for obstetrics was that of Hudon. ${ }^{2}$ The promising results obtained in that series induced the author and the members of his staff to pursue further investigation. The object of this paper is to give a detailed account of the clinical results obtained in a series of 500 unselected consecutive anaesthetics using methoxyflurane in obstetrics during 1961.

\section{TECHNIQUe}

Three different techniques were used. The first two techniques were performed in view of the possibility of the use of methoxyflurane outside of the hospital.

1. Use with Trilene Inhaler. Penthrane was substituted for Trilene in the inhaler and the mother performed her own anaesthesia during the first stages of labour. The analgesia obtained during pains was rapid in onset and highly satisfactory. Furthermore, Penthrane used in this way did not alter the rhythm and efficiency of the uterine contractions and consequently the progress of labour.

2. Open-drop technique. Open-drop methoxyflurane anaesthesia was carried out on five occasions with the Yankauer open-ether mask. Oxygen at the rate of $2-4$ liters per minute was delivered under the mask through a rubber catheter. The amount of drug necessary to induce and maintain the desıred level of anaesthesia (which extends from the first stage to the first plane of the third stage) was minimal (20 then 10 drops per minute). The induction was fast (unconsciousness supervened in a matter of 60 to 90 seconds).

This technique is perfectly suitable for deliveries at home under the supervision of the attending physician. It does not involve the toxic effects of chloroform nor the tedious side-effects of ether, though having a higher potency than Trilene. Its safety has been attested to by our nursing staff who, on a few occasions, were called upon to use it before the arrival of the anaesthesiologist.

3. Technique using the Heidbrink Ether Wick Vaporizer No. 8. Our previous experience with methoxyflurane in obstetrics had already taught us that induction and recovery were more rapid if nitrous oxide was added to oxygen and Penthrane. So, using a semiclosed technique, we induced anaesthesia with 4 litres of nitrous oxide, 2 litres of oxygen, and the Heidbrink ether vaporizer containing the Penthrane opened to marking 4,5 , or 6 (according to the response of the patient).

*From the Department of Anaesthesia, Hôtel-Dieu de Québec, Quebec.

Doctor Boisvert is now First Assistant in the Department of Anaesthesia of the Hospital St-Ambroise de Loretteville.

Can. Anaes. Soc. J., vol. 9, no. 4, July, 1962 
Wasmuth et al. ${ }^{1}$ report that concentrations of $0.4,0.5$, and 0.8 per cent respectively are obtained with these markings, when one uses a flow of 4 litres of oxygen. With this procedure, the proper level of anaesthesia is usually obtained within 1 to 3 minutes. We then decrease the nitrous oxide flow to 2 litres per minute and the methoxyflurane concentration to 0.2 or 0.4 per cent (markings 2 and 4 on the vaporizer).

If the obstetrician has an episiotomy or a forceps delivery to perform, the vaporizer is momentarily opened to marking 5 or 6 , in order to prevent movement on the part of the patient. Towards the end of the obstetrical procedure, the Penthrane concentration is progressively decreased so as to obtain rapid recovery of the patient.

This paper will deal with the 500 patients (Table I) anaesthetized according to the third and last technique described: gas-oxygen-methoxyflurane in Heidbrink ether wick vaporizer.

TABLE I

Classification of Patients According to Parity (500 patients)

\begin{tabular}{lcc}
\hline & Number & Percentage \\
\hline Primiparae & 138 & 276 \\
Gravidae II & 121 & 242 \\
Multiparae & 241 & 482 \\
\hline
\end{tabular}

\section{Premedication}

All the patients were given meperidine $50-100 \mathrm{mg}$. with scopolamine $0.4 \mathrm{mg}$. during labour. If those analgesics happened to be given within the hour before delivery, levallorphan tartrate $1 \mathrm{mg}$. was administered intravenously.

\section{Characteristics of Penthrane Anaesthesia is Obstetrics}

We shall divide this study into three main parts:

I. General characteristics of methoxyflurane.

II. Effects on the mother.

III. Effects on the child.

\section{General Characteristics}

Methoxyflurane possesses the great advantage of being non-flammable and non-explosive. This is a great asset in a delivery room. Besides, it it easy to administer and its odour is not objectionables. It can be used through a Trilene Inhaler, by open drop, or with any anaesthetic machine. It is relatively safé and non-toxic, coming next to ether in that respect. On the subject of potency, it comes close to halothane. It is also devoid of almost any noxious side-effect.

\section{Effects on the Mother}

1. Anaesthesia. The intensity and rapidity of onset of analgesia is remarkable, occurring within the first two minutes of Penthrane inhalation. It seems evident that anaesthesia is obtained much faster in obstetrical cases than in surgical cases. It is also obtainèd with much lower-indeed minimal-concentrations. 
Induction is pleasant, smooth, devoid of coughing or struggling. Maintenance is easy, the patient responding to painful stimuli by tachypnoea only.

The maintenance of the light-though sufficient-degree of anaesthesia proper to obstetrics requires some experience, because the classical signs of anaesthesia cannot be relied upon with methoxyflurane; the only constant signs are the size of the pupil and the central fixation of the eyeballs. But, after management of a few cases, the alert anaesthetist can have his patient wide awake on the delivery table within the first two minutes after completion of the obstetrical procedure. The golden rule is to avoid overdosage. The concentration sufficient to suppress the movements of the patient is the concentration to use: it will not hinder the progression of labour.

The postanaesthetic period is calm, free of anxiety and restlessness. Only two cases of chills-lasting respectively two and four minutes-occurred among our patients. Perineal and abdominal analgesia persists to varying degree for two hours after delivery. The typical patient wakes up rested, as if from natural sleep, with no recall whatsoever of the obstetrical procedure or of nightmares that could have occurred during anaesthesia. There is no evidence of stress, and there is a definite tendency to fall back into a quiet and refreshing sleep, which is greatly appreciated by the nursing staff.

2. Effects on the cardiovascular system. The cardiovascular signs-pulse, blood pressure-remained remarkably stable in all our patients. Two women with mitral stenosis went through anaesthesia without the slightest complication and the same applies to 9 patients suffering from pre-eclampsia at the time of delivery. Injection of oxytocics did not induce arrhythmias.

3. Effects on the gastrointestinal tract: vomiting. It is well known that vomiting, and the aspiration of vomitus into the tracheobronchial tree, is the most dreaded accident of obstetrical anaesthesia; so much so that the efficient anaesthetic agent that will eliminate vomiting will eventually take precedence over all the other anaesthetics.

Of those who vomited during anaesthesia (Table II), three (25 per cent) had had

TABLE II

Statistics Concerning Vomiting

\begin{tabular}{lcc}
\hline & Number of cases & Percentage \\
\hline Vomiting during anaesthesia & 12 & 24 \\
Vomiting after a naesthesia & 12 & 24 \\
\hline
\end{tabular}

ether with open mask prior to the arrival of the anaesthetist. One other case had vomited before and vomited after anaesthesia. It is worth mentioning that 9 patients who had vomited before anaesthesia did not do so either during or after anaesthesia with Penthrane. Furthermore, 5 patients had received ether before formal induction of anaesthesı with Penthrane and did not vornit. In only one of the 12 cases that vomited $₫$ during anaesthesia was a tracheo-bronchial toilet performed and not a single patient developed pulmonary complications. This 
may well be due to the preservation of the glottic reflex under light Penthrane anaesthesia.

A most interesting feature of methoxyflurane is that the injection of oxytocics (ergotrate, pitocin, etc.), even intravenously, did not elicit vomiting.

The reader has certainly noticed the incidence of 2.4 per cent of vomiting that followed termination of the anaesthesia with Penthrane. Vomiting occurred in a time interval extending from 10 minutes to 4 hours after the return of consciousness. This protracted type of vomiting seems to be a feature peculiar to methoxyflurane. All the other anaesthetics usually produce vomiting at awakening or in the immediate postanaesthetic period.

The percentage of vomiting found in our study compares favourably with that reported for cyclopropane $(42 \%)$ and Trilene $(28 \%)$, and even with that halothane $(4.6 \%){ }^{3}$

4. Effects on the pulmonary system. Methoxyflurane permits an induction devoid of coughing, hiccup, and orotracheal secretions. Not a single case of "cough and sputum," tracheobronchitis, bronchopneumonia, or hyperthermia secondary to pulmonary complications could be attributed to anaesthesia in our series. This can be accounted for by the very low incidence of vomiting, the apparent absence of regurgitation and silent vomiting, and the maintenance of the laryngotracheal protective reflexes associated with the use of light Penthrane anaesthesia. One could also suggest the possible antibacterial properties of Penthrane.

We did not observe, as during surgical anaesthesia, any depression of the pulmonary ventilation. Many factors explain this discrepancy. First the light plane of anaesthesia; second the increased dead space-and $\mathrm{CO}_{2}$ rebreathing-associated with the use of a mask; third the stimulation of ventilation from the labour pains. Should the plane of anaesthesia inadvertently be deepened and hypoventilation occur, breathing could be manually assisted, all the more easily for the fact that the perineolaryngeal reflex-often troublesome with cyclopropane and halothane at the same level of anaesthesia-is always markedly depressed, if not actually absent, under Penthrane anaesthesia.

5. Effects on muscular relaxation. A majority of the obstetricians pointed out that perineal relaxation was greater with Penthrane than with other anaesthetics. This relaxation-also evident in surgery--is commonly attributed to the direct action of methoxyflurane on the spinal cord. ${ }^{4}$

6. Effects on labour. It cannot be overemphasized that light Penthrane anaesthesia does not stop or depress uterine contractions. Actually, it often seens to stimulate and accelerate contractions by producing disappearance of the nervous patient's holding-back reaction and perhaps by permitting the exhausted patient to recuperate some degree of energy. If anaesthesia is skilfully conducted, expulsion can normally be produced by the parturient's own resources. Obstetricians are much impressed by this combination of effective anaesthesia and maintenance of efficient labour contractions.

The placenta was expelled, in 97.5 per cent of our cases, within 10 minutes of the birth of the baby, with only the occasional help of abdominal compression. Of the twelve cases where manual expulsion had to be performed, six were for 
actual retention of the placenta, the other six being for exploration of the uterine cavity for retention of membranes or placental parts.

As could be anticipated from the afore-mentioned observations, uterine atonia and consecutive haemorrhage proved exceptional with Penthrane. All blood loss exceeding $500 \mathrm{cc}$. during delivery was considered pathological. In all we had 10 such cases, and they all occurred in the obstetrical room. None of our ten cases of haemorrhage exceeded $900 \mathrm{cc}$, the average being $690 \mathrm{cc}$. Only two had to be given blood transfusions on the same day, and these two had a haemoglobin of $8 \mathrm{gm}$. on arrival at the hospital. The average blood loss for the 490 normal cases was $200 \mathrm{cc}$. In all instances where the uterus did not quite exhibit the desired tonicity after delivery and in all instances of pathological haemorrhage, the uterus responded with a strong and immediate contraction to the injection of oxytocics.

One should not forget, for all that has been said, that methoxyflurane is a powerful anaesthetic agent. As such, it can inhibit uterine contractions if given in sufficient concentrations. Deep methoxyflurane anaesthesia is valuable for intrauterine manipulations. We had the opportunity to use it with success in one case of Bandl ring contraction. Limited data do not permit more definite statements on the subject.

\section{Effects on the Child}

The main problem in obstetrical anaesthesia, besides vorniting on the part of the mother, is apnoea on the part of the baby. The present statistics (Table III)

TABLE III

TTME of OnSET OF Breathing

\begin{tabular}{|c|c|c|}
\hline & Number & Percentage \\
\hline First minute & 479 & 958 \\
\hline 1 to 2 minutes & 8 & 16 \\
\hline 2 to 3 minutes & 8 & 16 \\
\hline 3 to 4 minutes & 4 & 08 \\
\hline Longer & 3 & 06 \\
\hline
\end{tabular}

are based on 502 live births. There were 505 new-born babies: five sets of twins and three deaths in utero. Of the three babies under the heading "longer," one breathed spontaneously within 5 minutes, the other two within 15 and 30 minutes respectively.

It is well worth mentioning that, of the 479 babies that cried within the first minute, 420 (or $87 \%$ ) did so immediately after birth. Among the other 23 cases there were: 4 breech presentations, 6 labours exceeding 24 hours, 2 cases of tight and multiple coiling of the cord around the neck, 2 cases of prolapse of the cord, 3 cases of protracted deliveries involving intrauterine mainuplations; finally, the mother of one baby had received meperidine without levallorphan 45 minutes before delivery, while one baby developed hyaline membrane disease and another showed evidence of cardiac and other congenital malformations. Twelve of the 23 babies were born white and flaccid.

This leaves us with 3 cases in which no obvious obstetrical reason can be found that could reasonably be held responsible for the apnoea at birth (apnoea of 2 , 
3 , and 15 minutes respectively). Twenty-one of the 23 babies recovered very well from this initial phase of apnoea and did not show evidence of any cardiac, pulmonary, or neurologic sequelae. The two early neonatal deaths in our series were the baby with multiple malformations and the one with hyaline membrane disease. This amounts to a percentage that is very satisfactory. ${ }^{5}$

\section{Stmmary and CONClusions}

Methoxyflurane has been used for general anaesthesia in 500 unselected consecutive cases of vaginal deliveries. The outstanding features of the drug are the rapidity of induction, high level of analgesia under a light plane of anaesthesia, very low incidence of vomiting, minimal depression of uterine contractions, minimal respiratory depression of the foetus, quiet and rapid recovery.

In our opinion, it is the drug of choice in obstetrical anaesthesia. We are at the moment experimenting with the use of Penthrane in Caesarean sections and present data show it to be a promising agent.

\section{RÉSLMÉ}

Nous avons analysé les résultats obtenus avec l'anesthésie générale au méthoxyflurane dans 500 cas d'accouchements.

Nous avons décrit en premier lieu les techniques d'utilisation du Penthrane avec l'inhalateur à Trilène, avec le goutte à goutte et dans le vaporisateur à mèche Heidbrink no. 8. Nous soulignons ensuite les a vantages généraux de son utilisation en obstétrique.

Nous étudions en dernier lieu les effets du méthoxyflurane sur la mère et sur l'enfant. Le méthoxyflurane se signale par sa facilité et sa rapidité d'induction, son haut degré d'analgésie à un plan léger d'anesthésie et par le réveil calme qu'il assure. Ses effets cardiovasculaires sont négligeables et il réduit au minimum les vomissements per-anesthésiques $(2.4 \%)$. Aucune complication pulmonaire n'est survenue dans notre série de cas. Employé à faible concentration, il déprime très peu la contraction utérine. L'atonie et l'hémorrhagie utérines sont exceptionnelles, peu marquées, et réagissent très bien aux ocytociques. Dans ses effets sur l'enfant, le Penthrane se signale par un absence quasi complète de dépression respiratoire et cardiaque.

C'est l'anesthésique général de choix en obstétrique.

We are grateful to the Medical Department, Abbott Laboratories Limited, Montreal, for making available to us supplies of Penthrane (methoxyflurane).

\section{REFERENCES}

1. Wasmuth, C. E.; Greig, J. H ; Homi, J.; Moraca, P. P.; Isil, N. H.; Bitte, E. M.; \& Hale, D. E. Methoxyflurane-A New Anesthetic Agent: A Clinical Evaluation Based on 206 Cases. Cleveland Clinic Quart. 27: 174 (July 1960).

2. Hudon, F. Methoxyflurane. Canad. Anaesth. Soc. J. 8: 544 (1961)

3. Novoa, R. R. The Anti-Emetic Action of Fluothane: A Comparative Study in Obstetrical Anaesthesia. Canad. Anaesth. Soc. J. 7: 109 (1960).

4. NGaI, S. H. \& Hanks, E. C. Effect of Methoxyflurane on Electromyogram, Neuromuscular Transmission and Spinal Reflex. Anesthesiology 28, no. 1 (Jan.-Feb., 1962).

5. The Ontario Perinatal Mortality Study Commitee. Report of the Perinatal Mortality Study, 1959, in Ten I'niversity Teaching Hospitals, Ontario, Canada (November 1961). 